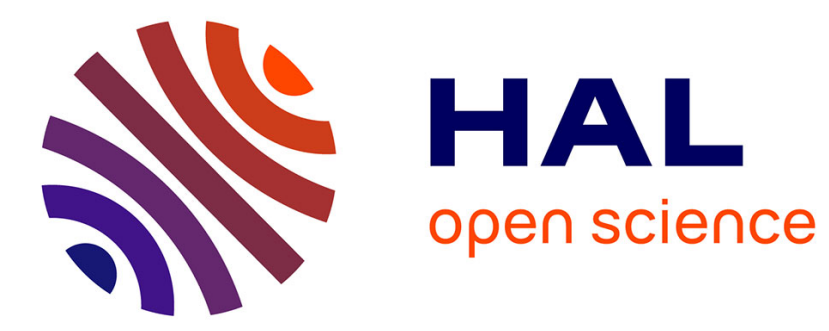

\title{
Anisotropic features of natural Teguline clay
}

Feng Zhang, Yu Jun Cui, Ling-Ling Zeng, Nathalie Conil

\section{To cite this version:}

Feng Zhang, Yu Jun Cui, Ling-Ling Zeng, Nathalie Conil. Anisotropic features of natural Teguline clay. Engineering Geology, 2019, 261, p105275. 10.1016/j.enggeo.2019.105275 . hal-02499355

\section{HAL Id: hal-02499355 https://hal.science/hal-02499355}

Submitted on 27 May 2021

HAL is a multi-disciplinary open access archive for the deposit and dissemination of scientific research documents, whether they are published or not. The documents may come from teaching and research institutions in France or abroad, or from public or private research centers.
L'archive ouverte pluridisciplinaire HAL, est destinée au dépôt et à la diffusion de documents scientifiques de niveau recherche, publiés ou non, émanant des établissements d'enseignement et de recherche français ou étrangers, des laboratoires publics ou privés. 


\section{Anisotropic features of natural Teguline clay}

\section{Feng Zhang ${ }^{1}$, Yu-Jun $\mathrm{Cui}^{1}$, Lingling Zeng ${ }^{2}$, Nathalie Conil ${ }^{3}$}

1: Ecole des Ponts ParisTech, Laboratoire Navier/CERMES, 6 et 8 avenue Blaise Pascal, 77455 Marne La Vallée cedex 2, France

2: Institute of Geotechnical Engineering, College of Civil Engineering, Fuzhou University, 350108 Fuzhou, China

3: CMHM, Andra, RD 960, 55290 Bure, France

\section{${ }^{*}$ Corresponding author:}

Prof. Yu-Jun CUI

Ecole des Ponts ParisTech

6-8 av. Blaise Pascal, Cité Descartes, Champs-sur-Marne

77455 Marne-la-Vallée cedex 2

France

E-mail : yu-jun.cui@enpc.fr

Tel: + 33164153550 
Abstract: In general, due to their geological formation by deposition, natural stiff clays exhibit anisotropic thermo-hydro-mechanical behaviour. This behaviour is important to be considered in geological and geo-environmental engineering. In this study, natural stiff Teguline clay was extracted at different depths and the thermal conductivity, compressibility and hydraulic conductivity were determined on samples along various orientations with respect to the bedding plane. Significant thermal and hydraulic conductivity anisotropies were evidenced with higher values along the bedding plane, indicating that both heat and water transfers preferentially occurred along the direction parallel to the bedding plane. Moreover, the compression index in the horizontal direction were found lower than in the vertical direction, while opposite phenomenon was observed for the yield stress. The degrees of thermal conductivity anisotropy $\eta_{\mathrm{T}}$, compression index anisotropy $\eta_{C \mathrm{c} 1}$, yield stress anisotropy $\eta_{\sigma_{\mathrm{y}}}$ and hydraulic conductivity anisotropy $\eta_{\mathrm{k} 1}$ were found comparable, indicating that bedding is a good indicator of the inherent thermo-hydro-mechanical anisotropy for natural stiff clays. Upon loading in oedometer after the yield stress, the inherent anisotropy changed: for the vertical sample (loading direction normal to the bedding plane), loading led to more and more anisotropy, while for the horizontal sample (loading direction parallel to the bedding plane), the inherent anisotropy disappeared first; then, the induced anisotropy was developed. These findings provided useful information for analyzing the thermo-hydro-mechanical anisotropy of natural soils in geotechnical and geo-environmental engineering.

Key words: Clays; Anisotropy; Thermal conductivity; Compressibility; Hydraulic 
conductivity

57 


\section{Introduction}

Due to their layered microstructure resulting from their initial deposition, natural stiff clays generally exhibit inherent anisotropy, which leads to directional dependence of their thermal, mechanical and hydraulic properties. This anisotropic feature is important to be accounted for while analysing the stability of the galleries excavated for geological nuclear waste disposal (Armand et al., 2013; François et al., 2014; Salehnia et al., 2015; Seyedi et al., 2017), because: i) during excavation, the damage of the host rock (thus the excavation damaged zone) is strongly depending on its anisotropy (Naumann et al., 2007; Niandou et al., 1997; Zhang et al., 2015); ii) after excavation, the stresses exerted to the concrete linings also strongly depend on the anisotropy by the surrounding host rock (Armand et al., 2013). This explains the particular attention paid recently to the anisotropic features of Boom Clay (Dao et al., 2014a; Dao et al., 2014b; Dao et al., 2015a; Dao et al., 2015b), Callovo-Oxfordian claystone (Armand et al., 2013; Zhang et al., 2015; Seyedi et al., 2017) and Tournemire shale (Niandou et al., 1997; Masri et al., 2014), and of Opalinus Clay (Naumann et al., 2007; Bertrand and Collin, 2017; Favero et al., 2018).

It has been well documented that for natural clays, the thermal conductivity and hydraulic conductivity in the horizontal direction are in general larger than in the vertical direction (Midttømme and Roaldset, 1999; Dao et al., 2014a), suggesting that the generally horizontal bedding planes are preferential flow directions for heat and fluids. Alshawmar (2014) carried out one-dimensional consolidation tests on undisturbed sensitive Champlain Sea clay and found that the ratio of horizontal to 
vertical preconsolidation pressure varied from 0.71 to 0.95 . Moreover, the horizontal compression index was $1 \%$ to $23 \%$, higher than the vertical one, showing a larger compressibility in the horizontal orientation. This can be attributed to the directional differences in soil fabric and in stress history during soil sedimentation (Khan, 1993). The natural clays (such as Opalinus Clay) also exhibited anisotropic features in terms of strength with higher value in the direction parallel and perpendicular to the bedding plane and lower value in the direction at $45^{\circ}$ to the bedding plane (Naumann et al., 2007).

It is also recognised that the anisotropic hydro-mechanical behavior is directly correlated to the microstructure features (Hicher et al., 2000; Zeng et al., 2017). Zeng et al. (2017) investigated the anisotropic swelling of Teguline clay associated with change in microstructure during wetting. The clay samples were allowed to swell freely or only in the vertical direction. The results showed that swelling occurred mainly in the direction perpendicular to the bedding plane, accompanied with the development of micro-fissures parallel to the bedding plane, the swelling along the bedding direction being negligible. The wetting-induced micro-fissures corresponded to the damage of soil, which could significantly modify the hydro-mechanical properties of soil in an anisotropic fashion.

Albeit the importance of anisotropy features recognised for natural soils from both academic and practical points of view, such results remain relatively limited, mainly because of the relatively large variability of natural soils that renders the interpretation of the test results difficult. This study aims at investigating the 
anisotropy feature of the thermo-hydro-mechanical behaviour of natural clays. Natural Teguline clay was considered for this purpose and its thermal conductivity, compressibility and hydraulic conductivity was determined in various orientations with respect to the bedding plane, which allowed the inherent anisotropy to be identified. Furthermore, the development of stress-induced anisotropy beyond the yield stress was also analyzed.

\section{Materials and methods}

\section{Test materials}

Stiff Teguline clay samples were extracted from borehole AUB1011 at depths of $18.21 \mathrm{~m}$ and $31.76 \mathrm{~m}$, also from borehole AUB1012 at depths of $5.46 \mathrm{~m}, 11.56 \mathrm{~m}$, $18.06 \mathrm{~m}, 30.5 \mathrm{~m}, 30.8 \mathrm{~m}$ and $31.22 \mathrm{~m}$, in the area of Albian Paris Basin (Aube, France), following the direction perpendicular to the bedding plane that was found to be parallel to the ground surface through observation of a piece of Teguline clay immersed in water. They were then covered by membrane and conserved in a fully confined cell (T1), preventing water loss and soil rebounding. This clay has a liquid limit of $42.0-56.5 \%$, a plastic limit of $17.5-29.4 \%$ and a specific gravity of 2.71 . The mineralogy was mainly defined by illite, illite-smectite, kaolinite, chlorite, quartz and carbonates (Zhang et al., 2018). The clay content and quartz content vary over depth, and their profiles are presented in Fig. 1. It can be observed that Teguline clay consists of $15-60 \%$ of clay minerals and $20-70 \%$ of quartz. It is worth noting that the tested Teguline clay cores were taken at the depths between $5 \mathrm{~m}$ and $40 \mathrm{~m}$. The clay content 
varied from $35 \%$ to $58 \%$ and the quartz content from $28 \%$ to $46 \%$, showing a certain variability of mineralogy.

\section{Thermal conductivity tests}

After opening the Teguline clay from the fully confined cell (T1) in the laboratory, the samples were prepared by trimming to reach the dimensions of $85 \mathrm{~mm}$ in diameter and $60 \mathrm{~mm}-90 \mathrm{~mm}$ in height. Then, they were covered by plastic film to avoid water loss by evaporation. The test program is presented in Table 1.

A thermal properties analyzer, $\mathrm{KD} 2$, was used to measure the thermal conductivity. Its principle is based on the transient hot-wire method. This device meets the requirements of ASTM Standards (ASTM D5334-00, 2000). In order to install the thermal probe into the soil, a hole was drilled in the centre of each sample. A layer of thermal grease was first applied on the surface of the probe to ensure a good contact between the soil and the probe. Then, the probe with grease was inserted into the sample. The thermal conductivity was measured in three orientations $\left(\theta=0^{\circ}\right.$, $\theta=90^{\circ}$, and $\theta=45^{\circ}$ to the bedding plane). For a better accuracy, five successive measurements were conducted and a mean value was considered for further analyses.

Due to the geological formation by deposition, the Teguline clay is considered as transversely isotropic material. In that case, the measured thermal conductivity $\lambda_{0}$ corresponds to that in the direction parallel to the bedding plane $\lambda / /$. However, in the case of $\theta=90^{\circ}$, the measured thermal conductivity $\lambda_{90}$ is not the value in the direction perpendicular to the bedding plane $\left(\lambda_{\perp}\right)$. The true value of $\lambda_{\perp}$ was thus back calculated using the following equation: 


$$
\lambda_{\perp}=\frac{\left(\lambda_{90}\right)^{2}}{\lambda_{0}}
$$

Davis et al., 2007; Dao et al., 2014a; Popov et al., 2012; Riche and Schneebeli, 2013;

Ye et al., 2017) to determine the thermal conductivity in the direction perpendicular to the bedding plane $\lambda_{\perp}$ in different materials (snow, igneous rocks, clay sediments, etc.).

The thermal conductivity of $\theta=45^{\circ}$ was calculated by Eq. (2) (Dao et al., 2014a):

$$
\lambda_{45}=\sqrt{\frac{\left(\lambda_{0}\right)^{2}+\left(\lambda_{90}\right)^{2}}{2}}
$$

The thermal conductivity of clays depends on the composition (solid, water and gas phases), the nature of the dominant minerals, the density and temperature (Farouki, 1986; Midttømme and Roaldset, 1999; Tang et al., 2008; Ye et al., 2017). The effect of the slightly decrease of degree of saturation $\left(S_{\mathrm{r}}\right)$ of the studied samples was accounted for according to the Johansen's method (Johansen, 1975; Farouki, 1986):

$$
\lambda_{\text {sat }}=\frac{\left(\lambda-\lambda_{\text {dry }}\right)}{K_{e}}+\lambda_{d r y}
$$

where $\lambda_{\text {sat }}, \lambda$ and $\lambda_{\text {dry }}$ expressed in $\mathrm{W} /(\mathrm{m} \cdot \mathrm{K})$ are respectively the thermal number. be determined by the following equations:

$$
K_{\mathrm{e}} \cong \log \left(S_{\mathrm{r}} / 100\right)+1.0
$$




$$
\lambda_{\mathrm{dry}}=\frac{0.135 \rho_{\mathrm{d}}+64.7}{\rho_{\mathrm{s}}-0.947 \rho_{\mathrm{d}}}
$$

where $S_{\mathrm{r}}$ is the degree of saturation, $\rho_{\mathrm{d}}$ is the dry unit mass of soil and $\rho_{\mathrm{s}}$ is the unit mass of solids, both expressed in $\mathrm{kg} / \mathrm{m}^{3}$.

The degree of thermal conductivity anisotropy $\eta_{\mathrm{T}}$ is defined as:

$$
\eta_{\mathrm{T}}=\frac{\lambda_{/ 1}}{\lambda_{\perp}}
$$

where $\lambda_{/ /}$(equal to $\lambda_{0}$ ) and $\lambda_{\perp}$ were respectively the thermal conductivities in the directions parallel and perpendicular to the bedding plane.

\section{Compressibility and hydraulic conductivity measurements}

The samples extracted from borehole AUB1012 at depths of $11.56 \mathrm{~m}$ and $30.5 \mathrm{~m}$, $30.8 \mathrm{~m}$ were used for the compressibility and the hydraulic conductivity measurements. Samples of $50 \mathrm{~mm}$ in diameter and $20 \mathrm{~mm}$ in height were prepared by trimming from two directions: horizontal direction and vertical direction. The test program is presented in Table 2 .

After installing the soil sample in oedometer cell, step loading was applied up to the in-situ effective vertical stress without putting the sample in contact with water in order to avoid soil swelling which would affect the soil microstructure and thereby the soil hydro-mechanical behavior (Delage et al., 2007; Cui et al., 2013). The in-situ effective vertical stress $\sigma_{\text {vo }}$ was estimated using Eq. (7):

$$
\sigma_{\mathrm{v} 0}^{\prime}=\gamma h-u_{0}
$$

where $\gamma$ is the mean unit weight of the soil above the depth considered, $h$ is the depth 
of the soil core (see Table 2); $u_{0}$ is the in-situ pore pressure estimated from the ground water level that is assumed to be at the ground surface for simplicity (Zhang et al., 2018).

The value of $\sigma_{\text {vo }}$ for AUB1012 extracted at $11.56 \mathrm{~m}$ was found to be $0.125 \mathrm{MPa}$. This value was applied to the sample trimmed in the horizontal and the vertical directions $(11.56 \mathrm{~m})$. The values of $\bar{\sigma}_{\text {vo }}^{\prime}$ for AUB1012 extracted at $30.8 \mathrm{~m}$ and $30.5 \mathrm{~m}$ were estimated at $0.34 \mathrm{MPa}$, which was applied to the sample trimmed in the horizontal $(30.8 \mathrm{~m})$ and the vertical $(30.5 \mathrm{~m})$ directions. It is worth noting that, experimentally, it is difficult to adopt an appropriate stress to be applied to the horizontal sample. Thus, for simplicity, the in-situ effective vertical stress applied to samples in both the horizontal and vertical directions. This also made the comparison between the responses of the samples in two directions easier.

After application of $\dot{\sigma}_{\text {vo }}$, the bottom porous stone and the drainage system were saturated with de-ionized water, and the sample was kept saturated for 1 week. Then, a constant water pressure of $0.1 \mathrm{MPa}$ was applied using a controller of pressure/volume (CPV) from the lower base of the cell, and the upper base was kept at atmospheric pressure. Based on the water flux monitored, the hydraulic conductivity was determined by the constant-head method. Afterwards, the injection pressure of $0.1 \mathrm{MPa}$ was reduced to $0.01 \mathrm{MPa}$, and the compression test was performed in a conventional way by step loading (see Table 2), up to $7.87 \mathrm{MPa}$ for AUB1012 at depth of $11.56 \mathrm{~m}$ in two directions and 16.08 MPa for AUB1012 at depths of $30.80 \mathrm{~m}$ in the horizontal direction and $30.50 \mathrm{~m}$ in the vertical direction. 
The hydraulic conductivity test was also performed after stabilization at each loading step. The axial displacement was monitored using a LVDT (Linear Variable Differential Transformer), and the deformation was considered as stabilized when the vertical strain rate was lower than $5 \times 10^{-4}$ every 8 h (AFNOR, 1997). Note that the compression curve of vertical sample (where loading occurred in the direction normal to the bedding plane) from AUB1012 (11.56 m) was collected from Zhang et al. (2018).

All the tests were performed at a controlled temperature of $20 \pm 1^{\circ} \mathrm{C}$.

\section{Experimental results}

\section{Thermal conductivity}

Since the values of degree of saturation were slightly lower than $100 \%$, the thermal conductivity values at saturated state were first calculated using Eqs. (3), (4) and (5). Figs. 2(a)-2(d) show the changes of thermal conductivity with dry density and water content along the three directions $\left(\lambda_{0}, \lambda_{45}, \lambda_{90}\right)$ for samples AUB1011 and AUB1012. The calculated values of $\lambda_{45}$ and $\lambda_{\perp}$ were also plotted. A good agreement was obtained between calculation and measurement in case of $\lambda_{45}$, justifying the calculation method adopted. A significant thermal anisotropy was identified with the highest thermal conductivity values in the direction parallel to bedding, the smallest ones in the direction perpendicular to bedding and the values in-between at $45^{\circ}$. This is consistent with the results reported by Dao et al. (2014a) on Boom Clay: the thermal conductivity in the horizontal direction was found to be higher than in the 
vertical direction. Moreover, the thermal conductivity along three directions $\left(\lambda_{0}\right.$, $\left.\lambda_{45}, \lambda_{90}\right)$ increased with the increase of dry density (Figs. $2 \mathrm{a}$ and $2 \mathrm{c}$ ), but decreased with the increase of water content (Figs. $2 b$ and $2 d$ ). This is commonly explained by the thermal conductivities of soil components (Tang et al., 2008): the thermal conductivity of solids $\left(\lambda_{\mathrm{s}}\right.$ is equal to $7.7 \mathrm{~W} /(\mathrm{m} . \mathrm{k})$ for quartz and $2.0 \mathrm{~W} /(\mathrm{m} . \mathrm{k})$ for other minerals) is much higher than that of water $\left(\lambda_{\mathrm{w}}=0.57 \mathrm{~W} /(\mathrm{m} . \mathrm{k})\right)$. Tang et al. (2008) worked on compacted MX80 bentonite and they also observed that the thermal conductivity increased with the increase of dry density and decreased with the increase of water content.

Figs. 3(a)-3(b) show the changes of degree of thermal conductivity anisotropy $\eta_{\mathrm{T}}$ with dry density and water content for samples AUB1011 and AUB1012. It appears that $\eta_{\mathrm{T}}$ varied from 1.49 to 1.65 for samples AUB1011 and from 1.23 to 1.55 for samples AUB1012. In addition, the degree of thermal conductivity anisotropy slightly decreased with dry density, but slightly increased with water content.

\section{Compressibility and hydraulic conductivity}

Fig. 4 presents the compression curves of samples AUB1012 in two directions and at two depths. It can be observed that slight swells occurred during saturation under the in-situ vertical stress $\sigma_{\text {vo }}$ for the four samples, suggesting that the in-situ stresses were slightly underestimated. By approximating each curve with two straight lines, the compression indexes $C_{\mathrm{c} 1}$ (corresponding to the common rebounding index $C_{\mathrm{s}}$ ) at lower stress and the compression indexes $C_{\mathrm{c} 2}$ (corresponding to the common 
compression index $C_{\mathrm{c}}$ ) at higher stress were determined. Meanwhile, the yield stresses $\sigma_{\mathrm{y}}$ (corresponding to the common pre-consolidation pressure $\sigma_{\mathrm{p}}{ }^{\prime}$ ) were determined as indicated by arrows in the figure. A degree of compression index anisotropy could be then defined either by $\eta_{C \mathrm{c} 1}$ (ratio of $C_{\mathrm{c} 1}$ in the vertical direction to $C_{\mathrm{c} 1}$ in the horizontal direction) or by $\eta_{C \mathrm{c} 2}$ (ratio of $C_{\mathrm{c} 2}$ in the vertical direction to $C_{\mathrm{c} 2}$ in the horizontal direction). Similarly, the degree of yield stress anisotropy $\eta_{\sigma \mathrm{y}}$ was defined as the $\sigma_{\mathrm{y}}$ in the horizontal direction divided by the one in the vertical direction. These parameters are reported in Table 3 . The $C_{\mathrm{c} 1}$ and $C_{\mathrm{c} 2}$ in the horizontal direction were found to be slightly lower than in the vertical direction, while opposite phenomenon was observed in terms of yield stress. For sample AUB1012 at $11.56 \mathrm{~m}$, the $\eta_{C \mathrm{c} 1}$ and $\eta_{\sigma \mathrm{y}}^{\prime}$ were respectively 2.14 and 1.86 , while for sample AUB1012 at $30.5 \mathrm{~m}$ and $30.8 \mathrm{~m}$, the two parameters were respectively equal to 2.43 and 2.21 . Interestingly, the values of $\eta_{C \mathrm{c} 2}$ were much lower, close to 1 , indicating that after yield, the vertical sample had similar compressibility with the horizontal one.

The hydraulic conductivity $k$ of Teguline clay in two directions and at two depths are shown in Fig. 5. For samples at $11.56 \mathrm{~m}$, the logarithm of hydraulic conductivity almost linearly increased with the void ratio in two directions. A significant hydraulic conductivity anisotropy was evidenced, with higher values in the horizontal direction. Further examination showed that for AUB 1012 at $11.56 \mathrm{~m}$, the distance between the lines in two directions gradually decreased after yielding, suggesting that the microstructures of the vertical sample and the horizontal one were getting closer. This phenomenon was not clear for AUB 1012 at $30.50 \mathrm{~m}$ and $30.80 \mathrm{~m}$. A degree of 
hydraulic conductivity anisotropy can be then defined either by $\eta_{\mathrm{k} 1}$ (ratio of $k_{1}$ in the horizontal direction to $k_{1}$ in the vertical direction at the same void ratio) before the yield stress or by $\eta_{\mathrm{k} 2}$ (ratio of $k_{2}$ in the horizontal direction to $k_{2}$ in the vertical direction at the same void ratio) after the yield stress. For samples AUB1012 at 11.56 $\mathrm{m}$, the $\eta_{\mathrm{k} 1}$ and $\eta_{\mathrm{k} 2}$ were respectively 1.73 and 1.5 , while for samples AUB1012 at 30.5 $\mathrm{m}$ and $30.8 \mathrm{~m}$, owing to the limited data before the yield stress in the horizontal direction, only $\eta_{\mathrm{k} 2}$ could be determined, which was about 2.0. This hydraulic conductivity anisotropy was also identified on Boom Clay (Yu et al., 2011): a $\eta_{\mathrm{\kappa}}$ of 1.86 was obtained with a hydraulic conductivity in the horizontal direction $\left(6.5 \times 10^{-12}\right.$ $\mathrm{m} / \mathrm{s})$, higher than in the vertical direction $\left(3.5 \times 10^{-12} \mathrm{~m} / \mathrm{s}\right)$.

In order to investigate the coupling effect between compressibility and permeability, the compression and hydraulic conductivity results are presented together in Fig. 6 in terms of normalized void ratio ele $e_{0}$ and normalized hydraulic conductivity $k / k_{0}$ versus the logarithm of vertical stress $\sigma_{\mathrm{v}}$ for samples AUB1012 at $11.56 \mathrm{~m}$ (Fig. 6(a)) and AUB1012 at $30.5 \mathrm{~m}, 30.8 \mathrm{~m}$ (Fig. 6(b)). The yield stresses in two directions are also indicated on the compression curves. It can be observed from Fig. 6(a) that: i) the normalized void ratio $e / e_{0}$ decreased with the vertical stress $\dot{\sigma}_{\mathrm{v}}$ in two directions and the decrease of $e / e_{0}$ in the vertical direction was found to be higher than in the horizontal direction; ii) the normalized $k / k_{0}$ decreased with the vertical stress $\dot{\sigma}_{\mathrm{v}}$ in two directions; a linear curve was observed in the vertical direction, while a nearly bi-linear curve was identified in the horizontal direction: when the stress was lower than a threshold stress of 1.91 MPa (higher than the corresponding yield stress 
of $1.04 \mathrm{MPa}$ ), the decrease of $k / k_{0}$ was small, and when the stress was higher than 1.91 $\mathrm{MPa}$, the decrease of $k / k_{0}$ was significantly larger; iii) upon loading below the threshold stress of $1.91 \mathrm{MPa}$, the decrease of $k / k_{0}$ in the horizontal direction was lower than in the vertical direction, which was consistent with the corresponding variation of $e / e_{0}$ versus $\sigma_{\mathrm{v}}$; by contrast, beyond the threshold stress of $1.91 \mathrm{MPa}$, the decrease of $k / k_{0}$ in the horizontal direction was higher than in the vertical direction, which was opposite to the corresponding variation of $e / e_{0}$ versus $\sigma_{\mathrm{v}}$, indicating that significant microstructure changes occurred upon loading beyond the threshold stress of 1.91 MPa for the horizontal sample. The similar phenomena were observed for the samples at depths $30.5 \mathrm{~m}$ and $30.8 \mathrm{~m}$ (in Fig. 6(b)).

\section{Discussion}

\section{Thermal conductivity}

As mentioned previously, quartz has significantly higher thermal conductivity than other minerals. Thus, the global thermal conductivity of soil $\lambda_{\mathrm{s}}$ is controlled by the volumetric fractions of quartz and other minerals, as follows (Tang et al., 2008):

$$
\lambda_{s}=\lambda_{q}^{v_{q}} \lambda_{o}^{1-v_{q}}
$$

where $\lambda_{\mathrm{q}}$ and $\lambda_{\mathrm{o}}$ are respectively the thermal conductivities of quartz $(7.7 \mathrm{~W} /(\mathrm{m} . \mathrm{K}))$ and other minerals $(2.0 \mathrm{~W} /(\mathrm{m} . \mathrm{K})) . v_{\mathrm{q}}$ is the volumetric fraction of quartz.

The thermal conductivity of soil also depends significantly on the arrangement of particles (Mcgaw, 1969; Hadley et al., 1984). Many models were used to predict the 
thermal conductivity (Mcgaw, 1969; Hadley et al., 1984), among which the series model which assumes perpendicular arrangement of conduction layers and the parallel model which assumes parallel arrangement of conduction layers allowed the lower and upper bounds of thermal conductivities to be defined, as follows:

$$
\begin{aligned}
& \lambda_{\text {series }}^{-1}=n \lambda_{w}^{-1}+(1-n) \lambda_{s}^{-1} \\
& \lambda_{\text {parallel }}=n \lambda_{w}+(1-n) \lambda_{s}
\end{aligned}
$$

where $n$ is the soil porosity; $\lambda_{\mathrm{w}}$ and $\lambda_{\mathrm{s}}$ are respectively the thermal conductivities of water and soil solid, expressed in $\mathrm{W} /(\mathrm{m} . \mathrm{K})$.

Fig. 7 presents the comparisons of thermal conductivities between the calculated (using the Eqs. (8), (9) and (10)) and the measured values. It is worth noting that, the measured $\lambda_{0}$ and calculated $\lambda_{\perp}$ (using Eq. (1) based on the measured $\lambda_{0}$ and $\lambda_{90}$ ) were considered as the measured values in the directions parallel and perpendicular to the bedding plane, respectively. In the calculation, the thermal conductivities of quartz, other minerals and water were taken equal to $7.7 \mathrm{~W} /(\mathrm{m} . \mathrm{K}), 2.0 \mathrm{~W} /(\mathrm{m} . \mathrm{K})$ and 0.57 $\mathrm{W} /(\mathrm{m} . \mathrm{K})$, respectively (Tang et al., 2008). The volumetric fractions of quartz, clay content were determined from Fig. 1 and the soil porosities were calculated from the dry densities (in Table 1). All results of samples AUB1011 and AUB1012 are considered in the analysis. The thermal conductivity results in Fig. 7(a) show that the series model gave satisfactory results, in particular while considering the quartz effect. On the contrary, the parallel model gave underestimation without considering the quartz effect and gave overestimation with consideration of quartz effect. 
340 other minerals in series in the direction perpendicular to the bedding plane. In that

341 case as less solid contacts could be expected, a lower thermal conductivity was

342 obtained. In the case of parallel model, heat flow took place through water quartz and

343 other soil minerals in the direction parallel to the bedding plane. As more solid

344 contacts were involved in that case, a higher thermal conductivity was expected. The

345 satisfactory results given by the series model with consideration of quartz effect (in

346 Fig. 7(a)) suggests that the volumetric fraction of quartz was important to be

347 accounted for. However, it appears that the parallel model with consideration of the 348 quartz effect overestimated the thermal conductivity (in Fig. 7(b)); thus in that case it

349 seems more suitable to not consider the quartz effect. In fact, the real soil arrangement

350 was neither fully in series, nor fully in parallel. Thus, in the case of series model the 351 consideration of quartz effect compensated the effect of soil particles and water that 352 are not in series, while in the case of parallel model the non-consideration of quartz 353 effect compensated to some extent the effect of soil particles and water that are not in 354 parallel.

Basically, compression in oedometer obeys $K_{0}$ condition. The value of $K_{0}$ can be estimated using the following equation (Della Vecchia et al., 2010; Lima et al., 2011;

$$
K_{0}^{S C}=\left(1-\sin \varphi^{\prime}\right) \sqrt{\mathrm{OCR}}
$$


where $K_{\mathrm{o}}^{\mathrm{SC}}$ is the earth pressure coefficient at rest for over-consolidation soil, $\varphi$ is the effective internal friction angle, OCR is the over-consolidation ratio. For Teguline clay extracted at $11.56 \mathrm{~m}$ and $30.5 \mathrm{~m}$, the OCRs are respectively 4.5 and 5.3 (determined from Fig. 4), and the effective internal friction angle $\varphi^{\prime}$ is about $27.3^{\circ}$ (Zhang et al., 2018). The $K_{\mathrm{o}}^{\mathrm{SC}}$ values determined using Eq. (11) are respectively 1.15 and 1.24 for samples extracted at $11.56 \mathrm{~m}$ and $30.5 \mathrm{~m}$, indicating that the maximum effective stress that Teguline clay had suffered in the horizontal direction in the history was expected to be higher than in the vertical direction. This is the reason why the yield stress in the horizontal direction was higher than in the vertical direction.

The degrees of anisotropy identified in terms of thermal conductivity, compression index, yield stress and hydraulic conductivity are not far from each other for the studied Teguline clay: $\eta_{\mathrm{T}}$ varied from 1.23 to $1.65, \eta_{\mathrm{Cc1}}$ from 2.14 to $2.43, \eta_{\sigma \mathrm{y}}^{\prime}$ from 1.86 to 2.21 and $\eta_{\mathrm{k} 1}$ was 1.73 . This indicates that bedding is a good indicator of thermo-hydro-mechanical anisotropy for natural stiff clays.

The compression curves (see Fig. 4) and hydraulic conductivities (see Fig. 5) in the horizontal and the vertical directions were found to gradually converge after yield, suggesting that the hydro-mechanical anisotropy of the horizontal sample was approaching that of the vertical one. As the microstructure of soil does not change significantly before the yield stress, the anisotropy identified represents the inherent one. On the contrary, significant microstructure change can be expected beyond the yield stress and in that case any anisotropy identified represents the induced one. Thereby, the large values of $\eta_{C \mathrm{c} 1}, \eta_{\sigma \mathrm{y}}$ and $\eta_{\mathrm{k} 1}$ obtained suggest a significant inherent 
anisotropy of Teguline clay, in agreement with the results of thermal conductivity. Upon loading beyond the yield stress, similar values of compression index $C_{\mathrm{c} 2}$ in two directions (see Table 3) were obtained. This does not indicate an isotropic behaviour; it just suggests that the microstructures of the vertical sample and the horizontal one were getting closer after yielding. The evolution of microstructure for vertical and horizontal Teguline clay samples during loading can be described in Fig. 8. For the vertical sample, loading in oedometer after the yield stress led to more and more anisotropic microstructure feature because of the expected increase of particle orientation (Delage and Lefebvra, 1984; Cui et al., 2013), while for the horizontal sample, the inherent anisotropy disappeared first upon loading; then, induced anisotropy developed with the increase of particle orientation. Thus, the changes of principle stresses (as if rotation of principal stresses took place) was involved in that case and the horizontal sample experienced changes from initial inherent anisotropy to isotropy and then to the stress-induced anisotropy.

The microstructure changes during loading for vertical and horizontal samples described in Fig. 8 were in agreement with the evolution of $k / k_{0}$ with $\dot{\sigma}_{\text {vo }}$ in semi-logarithmic plot (Figs. 6(a) and 6(b)). For the horizontal sample, the decrease of $k / k_{0}$ with $\dot{\sigma}_{\mathrm{v}}$ was small before the threshold stress, as the fluid flow in the direction parallel to the bedding is dominant and in that case the bedding plane acts as preferential path for water flow. By contrast, beyond the threshold stress, dramatic decrease of $k / k_{0}$ was observed, indicating that inherent anisotropy disappeared and induced anisotropy appeared with the increase of particle orientation. In that case, 
water flow in the direction normal to the induced orientated particles became prevailing. Thereby, for the horizontal sample, the threshold stress identified in the $k / k_{0}-\sigma_{\mathrm{v}}$ curve in semi-logarithmic plot separated the zone with prevailing parallel prevailing perpendicular flow (in the direction perpendicular to the induced orientated particles). This threshold stress should correspond to the stress that generated the

411 isotropic state in the soil. For the vertical sample, no clear threshold stress was

412 observed in the $k / k_{0}-\sigma_{\mathrm{v}}$ curve in semi-logarithmic plot. This is logical because loading 413 in oedometer after the yield stress led to more and more anisotropy and in that case the changes of perpendicular flow (in the direction perpendicular to the bedding plane before the yield stress and normal to the induced orientated particles after the yield stress) were dominant. 
horizontal direction. Moreover, the clay anisotropy was also characterized by higher values of yield stress in the horizontal direction than in the vertical direction.

The degrees of thermal conductivity anisotropy $\eta_{\mathrm{T}}$, compression index anisotropy $\eta_{C \mathrm{c} 1}$, the yield stress anisotropy $\eta_{\sigma \mathrm{y}}^{\prime}$ and hydraulic conductivity anisotropy $\eta_{\mathrm{k} 1}$ were not far from each other, suggesting that bedding is a good indicator of the inherent thermo-hydro-mechanical anisotropy for natural stiff clays.

Upon loading in oedometer, the inherent anisotropic features of Teguline clay changed after the yield stress: for the vertical sample, loading led to more and more particle orientation and thus more and more anisotropy. On the contrary, for the horizontal sample, loading led to the disappearance of the inherent anisotropy first, before creating the stress-induced anisotropy. The evolution of $k / k_{0}$ versus $\sigma_{\text {vo }}$ in semi-logarithmic plot also was found to be in agreement with the microstructure changes.

These findings confirm that natural stiff clays, through their formation by deposition, develop orientated microstructure. As a result, anisotropic features develop in terms of thermal conductivity, compressibility and hydraulic conductivity. These anisotropic features changed upon loading beyond the yield stress or the threshold stress. This anisotropy feature is important to be accounted for when constructing geotechnical and geo-environmental structures in natural stiff clays.

\section{References}

AFNOR., 1997. Sols: reconnaissance et essais. Essais oedométriques. Partie 1: Essai de compressibilité sur matériaux fins quasi saturés avec chargement par paliers. 
Alshawmar, F., 2014. Evaluation of compressibility, anisotropy and at-rest lateral earth pressure in Champlain Sea clays. Master thesis, University of Ottawa. Ottawa, Canada.

Armand, G., Noiret, A., Zghondi, J., Seyedi, D.M., 2013. Short- and long-term behaviors of drifts in the Callovo-Oxfordian claystone at the Meuse/Haute-Marne Underground Research Laboratory. J Rock Mech Geotech Eng. 5, 221-230.

ASTM D5334-00, 2000. Standard test methods for determining of thermal conductivity of soil and soft rock by thermal needle probe procedure. ASTM International, West Conshohocken, PA.

Bertrand, F., Collin, F., 2017. Anisotropic modelling of Opalinus Clay behaviour: From triaxial tests to gallery excavation application. J Rock Mech Geotech Eng. 9(3), 435-448.

Cui, Y.J., Nguyen, X.P., Tang, A.M., Li, X.L., 2013. An insight into the unloading/reloading loops on the compression curve of natural stiff clays. Appl. Clay Sci. 83-84, 343-348.

Davis, M.G., Chapman, D.S., Van Wagoner, T.M., Armstrong, P.A., 2007. Thermal conductivity anisotropy of metasedimentary and igneous rocks. J. Geophys. Res. 112 (B05216), 1-7.

Dao, L.Q., Delage, P., Tang, A.M., Cui, Y.J., Pereira, J.M., 2014a. Anisotropic thermal conductivity of natural Boom Clay. Appl. Clay Sci. 101, 282-287.

Dao, L.Q., Cui, Y.J., Tang, A.M., Pereira, J.M., Li, X.L., Sillen, X., 2014b. Investigating the anisotropy of the shear modulus of natural Boom Clay. Geotech Lett. 4, 98-101.

Dao, L.Q., Cui, Y.J., Tang, A.M., Delage, P., Li, X.L., Sillen, X., 2015a. Anisotropy in Oedometer Test on Natural Boom Clay. Engineering Geology for Society and Territory. 6, 499-502.

Dao, L.Q., Cui, Y.J., Tang, A.M., Pereira, J.M., Li, X.L., Sillen, X., 2015b. Impact of excavation damage on the thermo-hydro-mechanical properties of natural Boom Clay. Eng Geol. 195, 196-205.

Delage, P., Lefebvre, G., 1984. Study of the structure of a sensitive Champlain clay and of its evolution during consolidation. Can. Geotech J. 21(1), 21-35.

Delage, P., Le, T.T., Tang, A.M., Cui, Y.J., Li, X.L., 2007. Suction and in-situ stresses of deep Boom clay samples. Géotechnique. 57(1), 239-244.

Della Vecchia, G., Lima, A., Jommi, C., and Romero, E. 2010. Some remarks on the hydro-mechanical constitutive modelling of natural and compacted Boom clay. Proc. 5th Int. Conf. on Unsaturated Soils. Barcelona. Taylor and Francis Group, London, 803-809.

Farouki, O.T., 1986. Thermal properties of soils. Rock and Soil Mechanics 11. Trans Tech Publications, Clausthal-Zellerfeld, Germany.

Favero, V., Ferrari, A., Laloui, L., 2018. Anisotropic behaviour of Opalinus Clay through consolidated and drained triaxial testing in saturated conditions. Rock Mech Rock Eng. 51(5), 1305-1319.

Francois, B., Labiouse, V., Dizier, A., Marinelli, F., Charlier, R., Collin, F., 2014. 
Hollow Cylinder Tests on Boom Clay: Modelling of Strain Localization in the Anisotropic Excavation Damaged Zone. Rock Mech Rock Eng. 47, 71-86.

Hadley, G.R., Mcvey, D.F., Morinl, R., 1984. Thermophysical properties of deep ocean sediments. Marine Geotechnology. 5(3-4), 257-295.

Hicher, Y.P., Wayudi, H., Tessier, D., 2000. Microstructural analysis of inherent and induced anisotropy in clay. Mech Cohes-frict Mat. 5(5), 341-371.

Johansen, O., 1975. Thermal conductivity of soils. Ph.D. thesis, Trondheim, Norway. (CRREL Draft Translation 637, 1977). ADA 044002.

Khan, M.M.A., 1993. Strength-deformation behaviour of a weathered clay crust. PhD thesis, University of Ottawa, Ottawa, Canada.

Lima, A., Romero, E., and Piña, Y. 2011. Water retention properties of two deep Tertiary clay formations within the context of radioactive waste disposal. VII Brazilian Symposium on Unsaturated Soil. Pirenópolis, Goiania, Brazil, 315-321.

Masri, M., Sibai, M., Shao, J.F., Mainguy, M. 2014. Experimental investigation of the effect of temperature on the mechanical behavior of Tournemire shale. Int J Rock Mech Min Sci. 70, 185-191.

Mcgaw, R., 1969. Heat conduction in saturated granular materials. High research board sepcial report. 103, 114-131.

Midttømme, K., Roaldset, E., 1999. Thermal conductivity of sedimentary rocks: uncertainties in measurement and modeling. Geol. Soc. Lond., Spec. Publ. 158(1), 45-60.

Munroe, R.J., Sass, J.H., 1987. Thermal Conductivity of Samples From Borehole VC-1, Report 87-184. Geological Survey.

Naumann, M., Hunsche, U., Schulze, O., 2007. Experimental investigations on anisotropy in dilatancy, failure and creep of Opalinus Clay. Phys. Chem. Earth. 32(8-14), 889-895.

Niandou, H., Shao, J.F., Henry, J.P., Fourmaintraux, D., 1997. Laboratory investigation of the mechanical behaviour of Tournemire shale. Int J Rock Mech Min Sci. 34(1), 3-16.

Penner, E., 1963. Anisotropic thermal conduction in clay sediments. International Clay Conference.

Popov, Y., Bayuk, I., Parshin, A., Miklashevskiy, D., Novikov, S., Chekhonin, E., 2012. New methods and instruments for determination of reservoir thermal properties. Proceedings Thirty-seventh Workshop on Geothermal Reservoir Engineering. Stanford University, Stanford, California.

Riche, F., Schneebeli, M., 2013. Thermal conductivity of snow measured by three independent methods and anisotropy considerations. The Cryosphere. 7, 217-227.

Salehnia, F., Collin, F., Li, X.L., Dizier, A., Sillen, X., Charlier, R., 2015. Coupled modeling of Excavation Damaged Zone in Boom clay: Strain localization in rock and distribution of contact pressure on the gallery's lining. Comput Geotech. 69, 396-410.

Seyedi, D.M., Armand, G., Noiret, A., 2017. "Transverse Action"- A model 
benchmark exercise for numerical analysis of the Callovo-Oxfordian claystone hydromechanical response to excavation operations. Comput Geotech. 85, 287-305.

Tang, A.M., Cui, Y.J., Le, T.T., 2008. A study on the thermal conductivity of compacted bentonites. Appl. Clay Sci. 41, 181-189.

Ye, W.M., Lu, Y., Huang, X.H., Chen, B., Chen, Y.G., Cui, Y.J., 2017. Anisotropic thermal conductivity of unsaturated compacted GMZ bentonite-sand mixture. PanAm Unsaturated Soils. 413-424.

Yu, L., Gedeon, M., Wemaere, I., Marivoet, J., De Craen, M., 2011. Boom clay hydraulic conductivity. A Synthesis of 30 Years of Research. External Report SCK-CEN, Mol (Belgium).

Zhang, C.L., Armand, G., Conil, N., 2015. Investigation on the anisotropic mechanical behaviour of the Callovo-Oxfordian clay rock. Final report.

Zhang, F., Cui, Y.J., Zeng, L.L., Robinet, J.C., Conil, N., Talandier, Jean., 2018. Effect of degree of saturation on the uncondined compressive strength of natural stiff clays with consideration of air entry value. Eng. Geol. 237, 140-148.

Zeng, L.L., Cui, Y.J., Conil, N., Zghondi, J., Armand, G., Talandier, J., 2017. Experimental study on swelling behaviour and microstructure changes of natural stiff clays upon wetting. Can. Geotech J. 54(5), 700-709.

\section{List of Tables}

Table 1. Program for thermal conductivity tests

Table 2. Program for compressibility and hydraulic conductivity tests

Table 3. Parameters obtained from the compression curves

\section{List of Figures}

Fig. 1. Variations of (a) clay content; (b) quartz content over depth

Fig. 2. Variations of thermal conductivity with (a) dry density for samples AUB1011; (b) water content for samples AUB1011; (c) dry density for samples AUB1012; (d) water content for samples AUB1012

Fig. 3. Variations of degree of thermal conductivity anisotropy $\eta_{T}$ with (a) dry density; (b) water content

Fig. 4. Compression curves

Fig. 5. Hydraulic conductivity $k$ versus void ratio $e$

Fig. 6. Normalized $e / e_{0}$ or $k / k_{0}$ versus vertical stress $\sigma_{\mathrm{v} 0}$ for samples (a) AUB1012 at $11.56 \mathrm{~m}$; (b) AUB1012 at $30.5 \mathrm{~m}$ and $30.8 \mathrm{~m}$

Fig. 7. Comparisons of measured thermal conductivity and calculated values by (a) 
600

601

602 603

series model; (b) parallel model

Fig. 8. Conceptual model for vertical sample and horizontal sample subjected to loading in one-dimensional condition 
Table 2. Program for compressibility and hydraulic conductivity tests

\begin{tabular}{lccc}
\hline Core & Depth $(\mathrm{m})$ & Direction & Stress path (MPa) \\
\hline & 11.56 & Horizontal & 0.125-0.375-0.874-1.874-3.872-7.869 \\
AUB1012 & Vertical & \\
\cline { 2 - 4 } & 30.8 & Horizontal & \\
& 30.5 & Vertical & $0.345-0.594-1.094-2.093-4.092-8.089-16.083$ \\
\end{tabular}

607

608

609

610

611

Table 3. Parameters obtained from the compression curves

\begin{tabular}{cccccccc}
\hline Core & Direction & $C_{\mathrm{C} 1}$ & $\eta_{C \mathrm{c} 1}$ & $\sigma_{\mathrm{y}}^{\prime}$ & $\eta_{\sigma \mathrm{y}}^{\prime}$ & $C_{\mathrm{C} 2}$ & $\eta_{\mathrm{Cc} 2}$ \\
\hline & Horizontal & 0.0081 & & 1.04 & & 0.074 & \\
AUB1012 $11.56 \mathrm{~m}$ & Vertical & 0.0173 & & 0.56 & & 0.081 & \\
\hline AUB1012 30.8 m & Horizontal & 0.0042 & & 3.97 & & 0.064 & \\
& & & 2.43 & & 2.21 & & 1.14 \\
AUB1012 30.5 m & Vertical & 0.0102 & & 1.80 & & 0.073 & \\
\hline
\end{tabular}

612

613

614

615

616

617

Note that the horizontal direction refers to the loading direction parallel to the bedding plane, while the vertical direction refers to the loading direction normal to the bedding plane. 


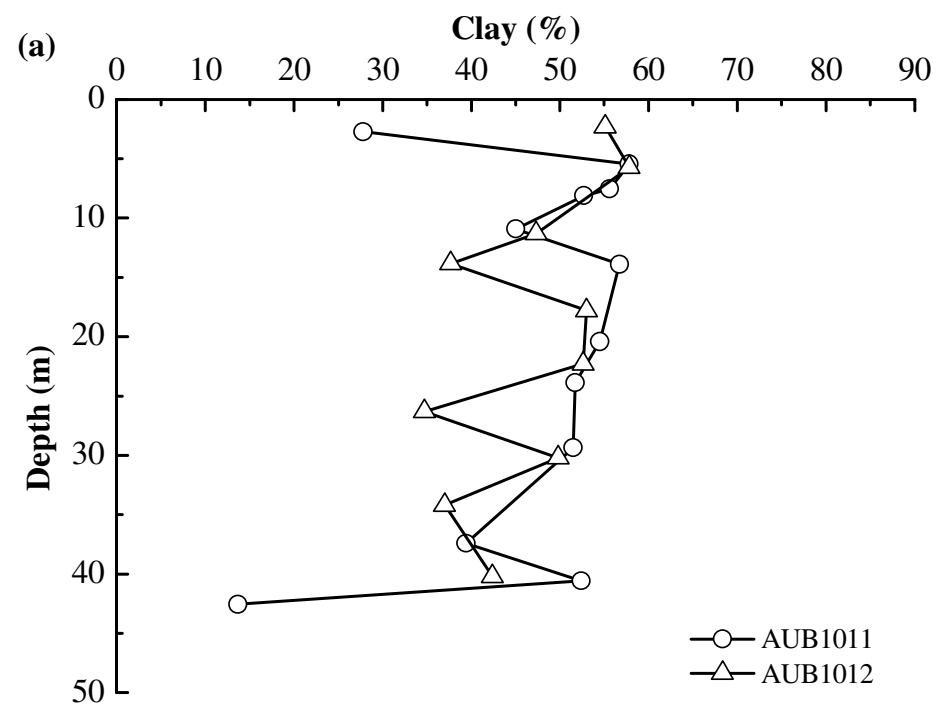

(b) \begin{tabular}{llllllllll}
\multicolumn{1}{c}{ Quartz (\%) } \\
0 & 10 & 20 & 30 & 40 & 50 & 60 & 70 & 80 & 90
\end{tabular}

Fig. 1. Variations of (a) clay content; (b) quartz content over depth 621
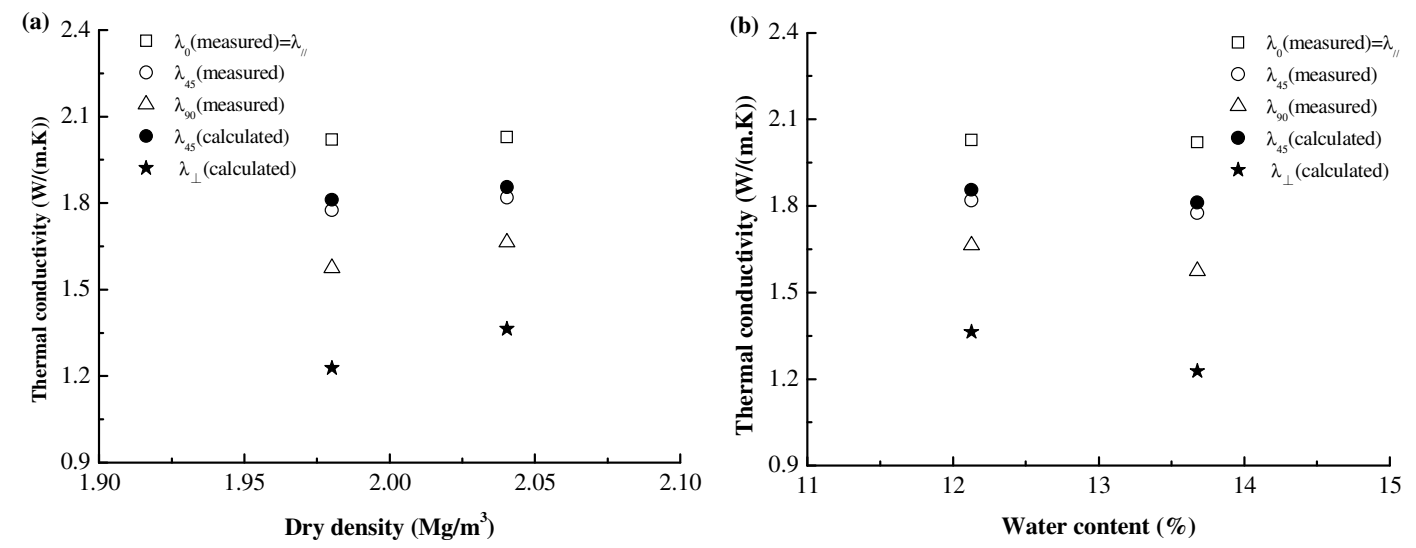

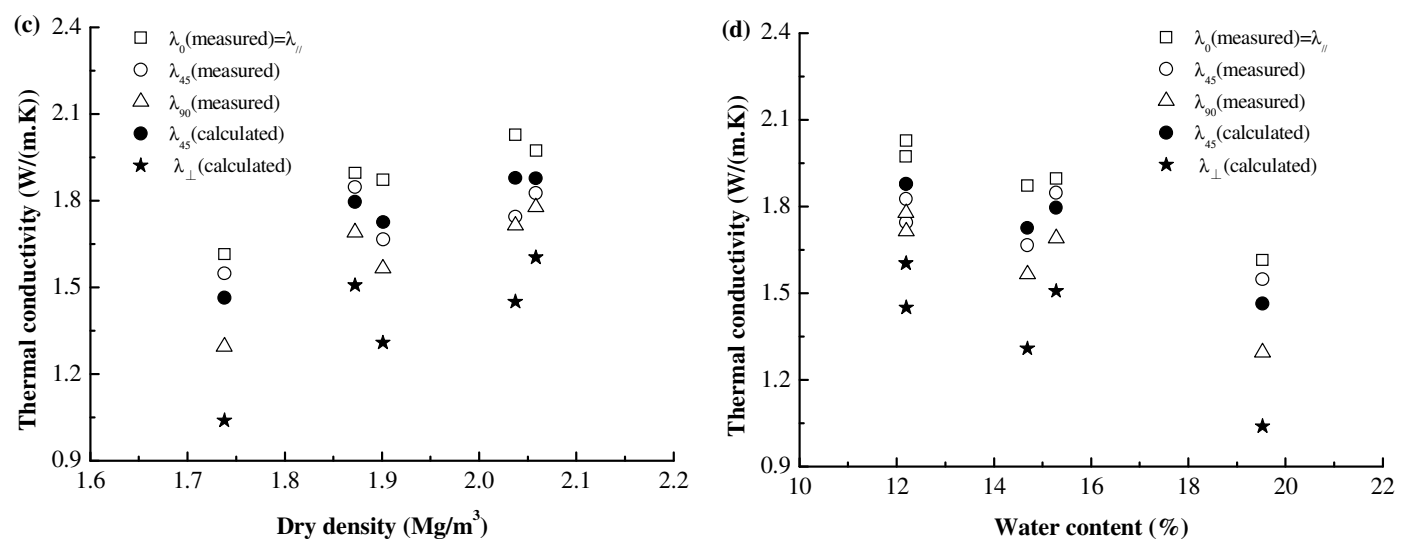

623

624

625 626

Fig. 2. Variations of thermal conductivity with (a) dry density for samples AUB1011;

(b) water content for samples AUB1011; (c) dry density for samples AUB1012; (d)
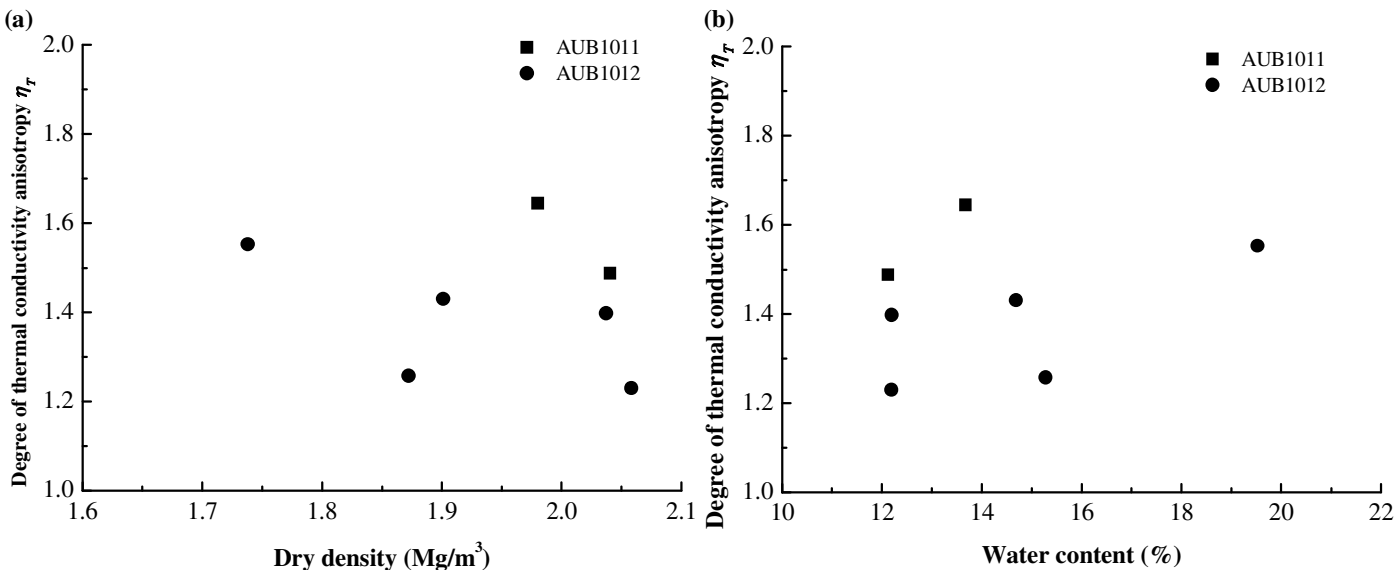

Fig. 3. Variations of degree of thermal conductivity anisotropy $\eta_{T}$ with (a) dry density; (b) water content

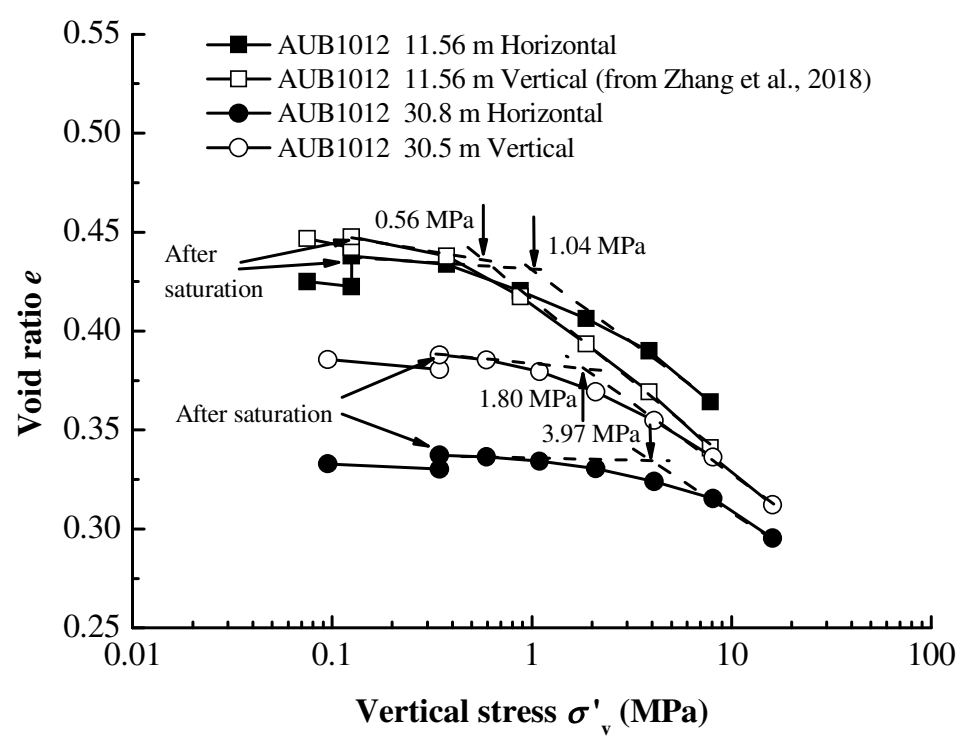

630

Fig. 4. Compression curves 


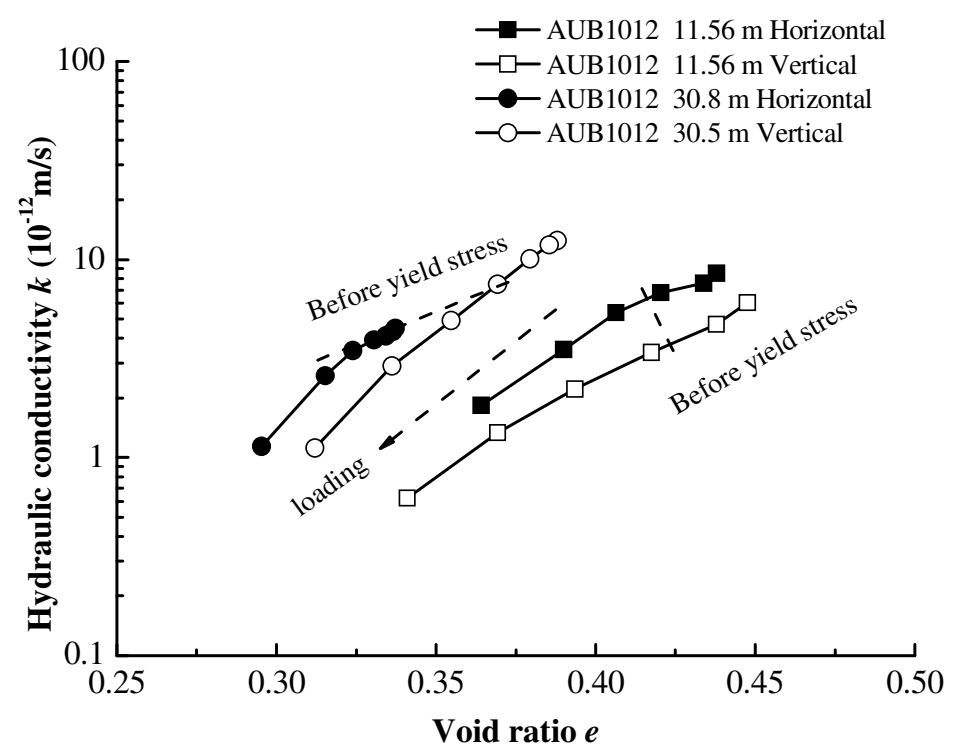

632

Fig. 5. Hydraulic conductivity $k$ versus void ratio $e$

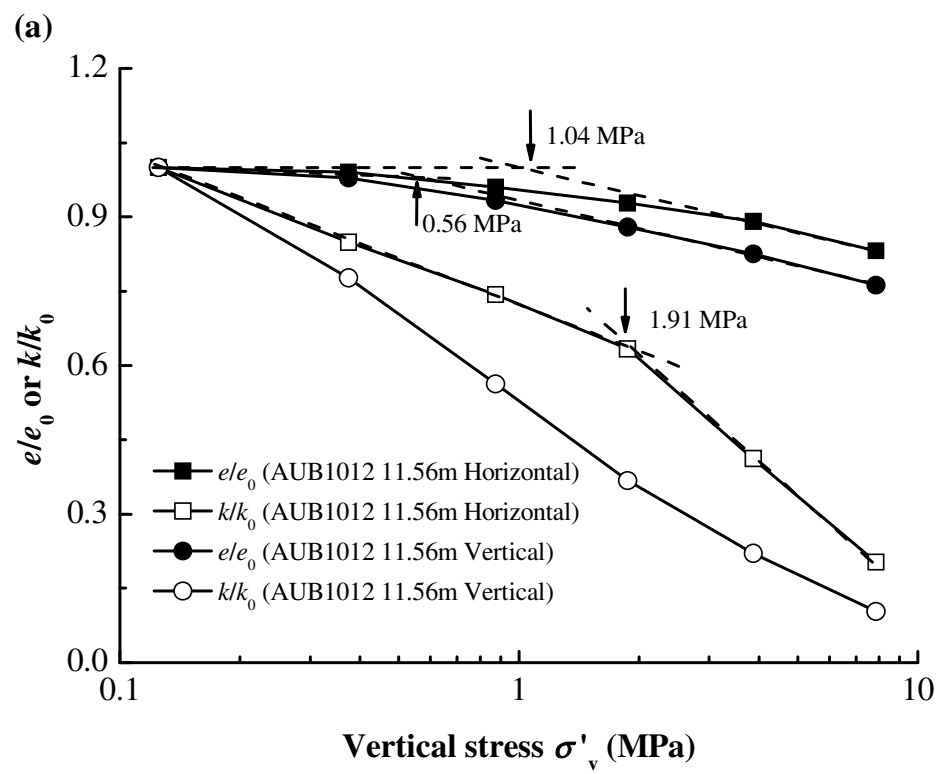




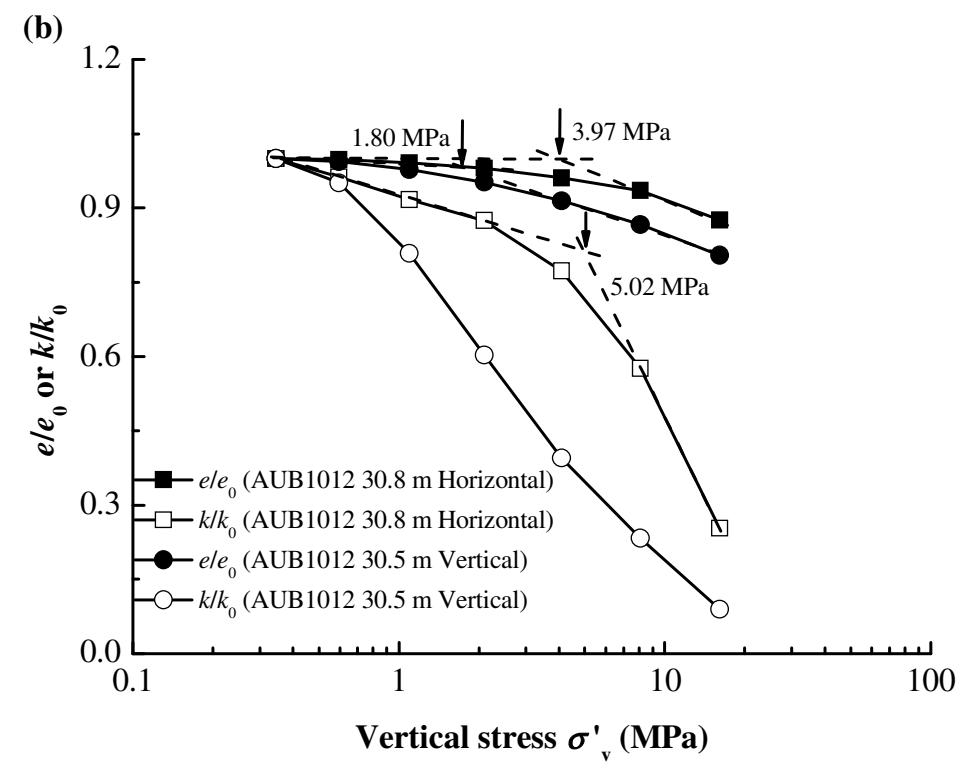

635

636 Fig. 6. Normalized $e / e_{0}$ or $k / k_{0}$ versus vertical stress $\sigma_{\mathrm{v} 0}$ for samples (a) AUB1012 at 637 $11.56 \mathrm{~m}$; (b) AUB1012 at $30.5 \mathrm{~m}$ and $30.8 \mathrm{~m}$

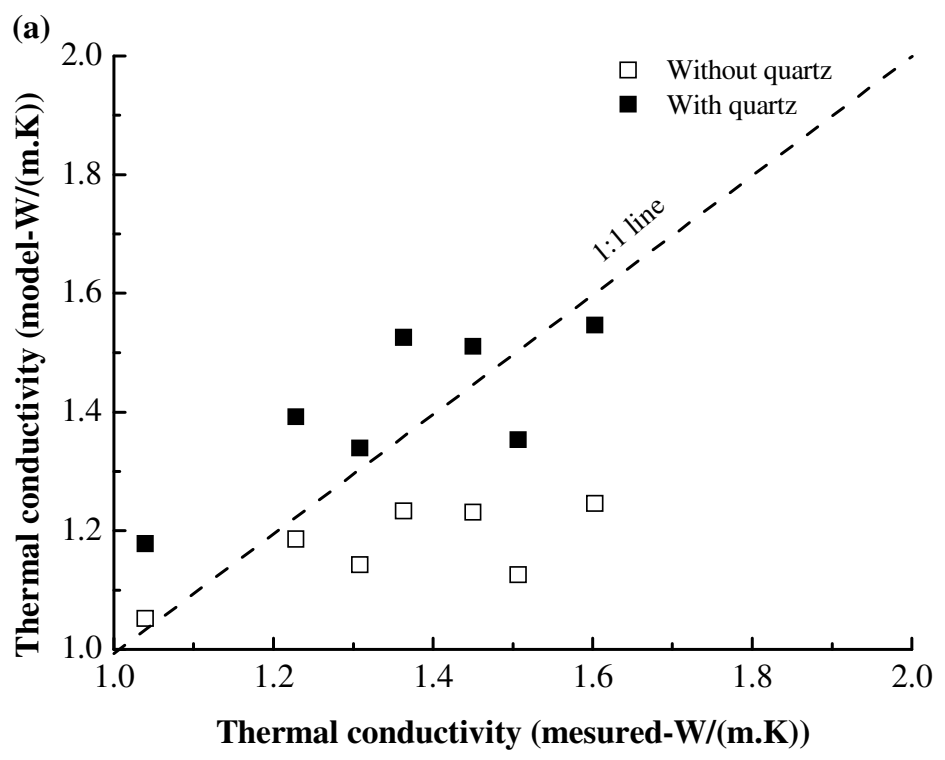

638 


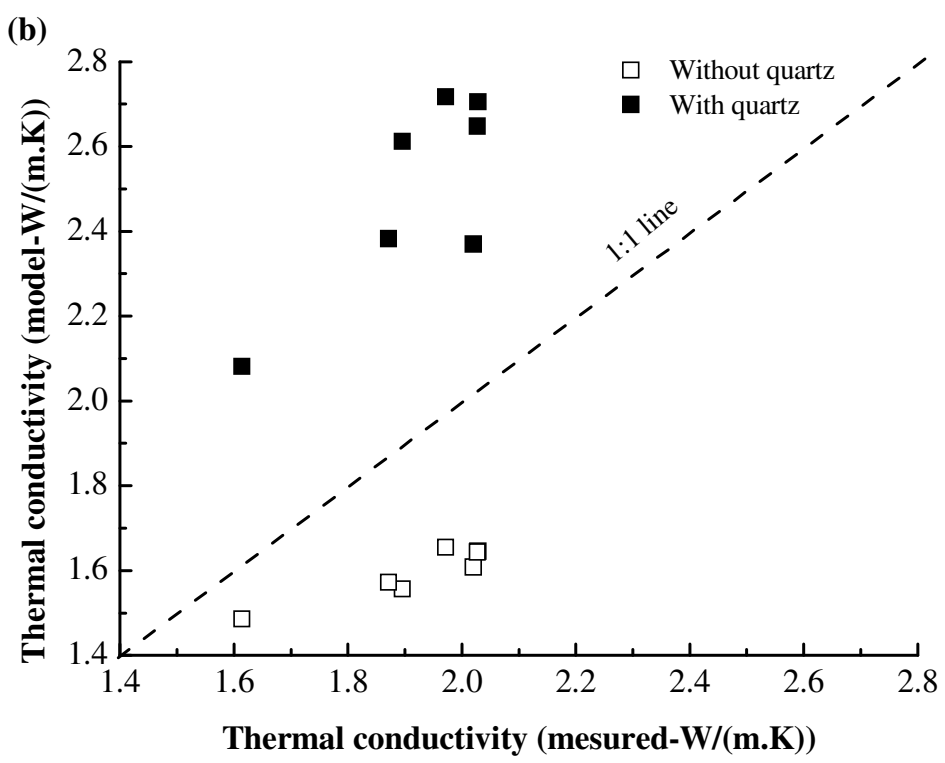

639

640 Fig. 7. Comparisons of measured thermal conductivity and calculated values by (a) 641 series model; (b) parallel model

642

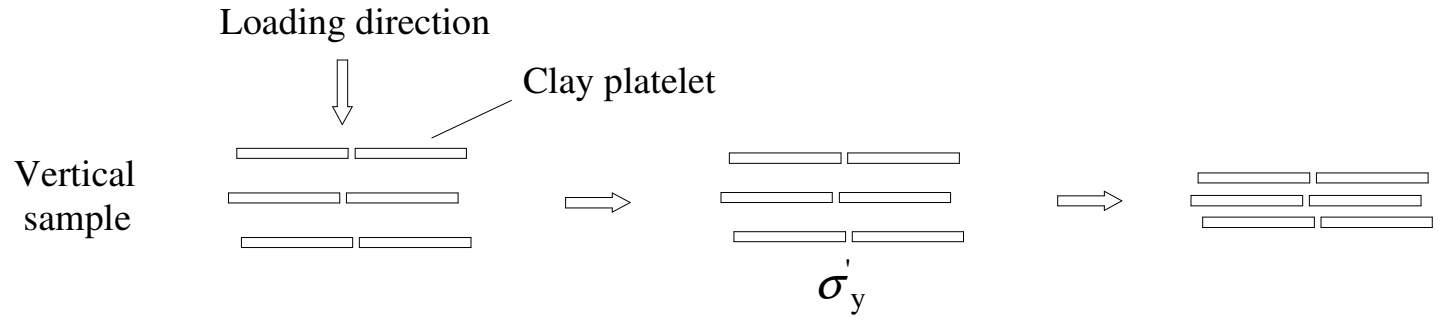

Loading direction

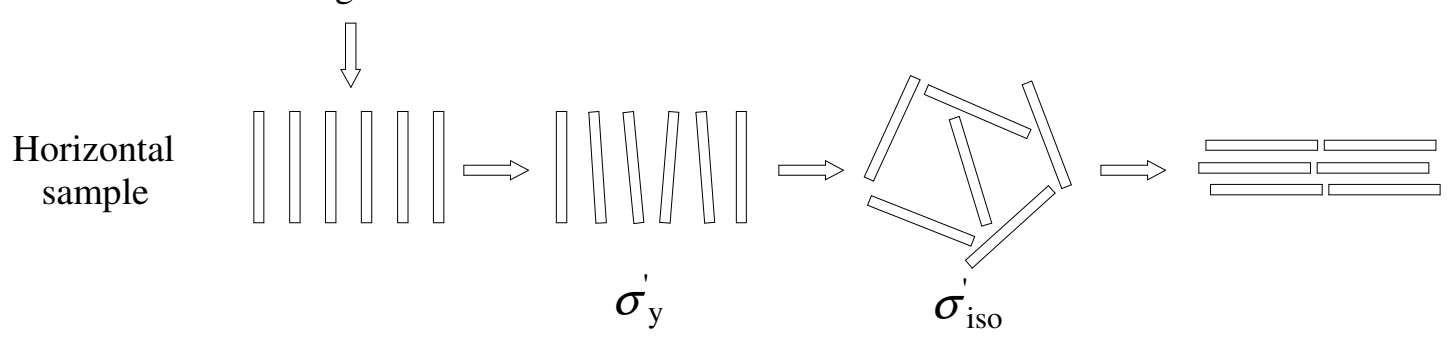

643

Fig. 8. Conceptual model for vertical sample and horizontal sample subjected to 645 loading in one-dimensional condition

646 